\title{
Laparoscopic sacrocolpopexy: results of a 100-patient series with 8 years follow-up
}

Published online: 25 February 2004

(C) Springer-Verlag Berlin / Heidelberg 2004

\begin{abstract}
Objective: Assess the feasibility, safety and results at mean term of laparoscopic promontofixation, and to describe the operative technique. Design: Retrospective study. Setting: Department of Gynaecology, Obstetrics and Reproductive Medicine, Caen University Hospital, France. Sample: One hundred patients included from June 1993 to June 2001. Methods: Pre- and postoperative clinical assessment of pelvic statics problems in accordance with the international POP-Q classification. Annual follow-up of patients and recording of any adverse effects. Main outcome measures: The number of per-operative, immediate and late post-operative complications, together with the number of cases of recurrent prolapse. Results: The mean follow-up was 43 months with one patient lost to follow-up. The rate of per operative complications was 11\% (injuries: 6 bladder; 1 ureter; 1 vaginal; 1 rectal; 2 vascular) with a $4 \%$ rate of conversion to laparotomy. The rate of early post-operative complications was $9 \%$, involving 7 patients (4 urinary infections, 3 occlusion syndromes, 1 eventration at a port site, 1 case of lumbo-sacral pain). The rate of late post operative complications was $25 \%$, involving 24 patients (3 vaginal erosions, 2 volvulus of ileum, 5 cases of urinary stress incontinence, 14 cases of de novo constipation and 1 case of chronic pelvic pain). The success rate was $96 \%$ with 6 cases of partial recurrence (4 cystoceles and 2 rectoceles). Conclusions: Laparoscopic pro-montofixation is feasible and safe. The rates of complications and recurrence are comparable to those reported in the literature for procedures carried out by laparotomy. The advantages connected with endoscopic surgery are the reduced trauma to the abdominal wall and the improved anatomical vision provided by the optic fibres; however, the long learning curve means that this procedure should
\end{abstract}

P. von Theobald $(\bullet) \cdot$ A. Chéret

Department of Gynecology Obstetrics and Reproductive Medicine, University Hospital of Caen, Boulevard Georges Clémenceau, 14033 Caen cedex, France

e-mail: vontheobald-p@chu-caen.fr

Tel.: +33-2-31272533

Fax: +33-2-31272337 be reserved for confirmed practitioners of laparoscopic surgery.

Keywords Prolapse $\cdot$ Laparoscopy $\cdot$ Sacrocolpopexy

\section{Introduction}

Since the end of the 1950s two different standard methods for surgical management of genital prolapse have competed with each other: the vaginal approach for fascia repair, reinforcing the structures using autologous tissues; and the abdominal method, whether endoscopic or not, reinforcing the fascia and using prostheses for suspension. The surgical goals are simple and identical: to correct each element contributing to the prolapse and any associated urinary problems $[1,2]$, but the multiplicity of techniques available is in itself proof of how difficult the question is $[3,4,5,6]$. In addition to differences between schools, the less aggressive vaginal method, despite its high rate of recurrence, was more indicated for elderly, less active patients who are more fragile with respect to anaesthesia and major surgery.

The abdominal route was used more for younger women in whom the use of a prosthesis was a guarantee that the repair would remain good for a longer period. The development of laparoscopic sacrocolpopexy has enabled the invasive nature of the operation to be reduced but requires a higher level of technical skill.

The purpose of this article is to report on 8 years of experience with laparoscopic promontofixation in order to assess the feasibility, safety and results.

\section{Materials and methods}

One hundred patients of mean age 55 years (range 25-75 years) underwent operative laparoscopy between June 1993 and June 2001 for correction of prolapse, whether recurrent $(n=27)$ or not $(n=73)$, by the same team using the same technique. All women under 68 years and presenting prolapse, and all women whatever their age presenting recurrent prolapse after correction by vaginal surgery, 
Table 1 Staging of the prolapse according to the international POP-Q classification [7]

\begin{tabular}{lll}
\hline & Stage: no. of patients & Stage: no. of patients \\
\hline Vault & III C: 16 & IV C: 9 \\
Hysterocele & III C: 46 & IV C: 19 \\
Cystocele & III Ba: 55 & IV Ba: 11 \\
Rectocele & III Bp: 49 & IV Bp: 4 \\
\hline
\end{tabular}

were included. Women who could not withstand the general anaesthesia, pneumoperitoneum and Trendelenburg position required by this operation were excluded. The mean parity in our series was 2.9. Nineteen patients had given birth to large babies (weight over $4000 \mathrm{~g}$ ). Two patients had given birth by caesarean section only, and 9 with the help of forceps. Nine patients in this series presented $\mathrm{BMI}>32$. Of the 45 women past the menopause, 10 were taking no replacement hormone therapy. Twenty-seven patients had already undergone one or more surgical operations to correct their prolapse via the vaginal route and 9 other patients had already been operated to correct stress urinary incontinence only. Of the 100 patients, 25 had already undergone total hysterectomy and 2 sub-total hysterectomy. The appearance of the prolapse and a dragging sensation in the pelvis were the most frequent reasons for consultation $(n=72)$. Twenty-one patients consulted for stress urinary incontinence and 6 for recurrence after surgical correction of urinary incontinence. One patient presented very disabling deep dyspareunia that was the reason for her consultation. Clinical examination and staging of the prolapse took place in accordance with the international POP-Q classification approved by the International Continence Society [7] and are summarized in Table 1. Seventy-six women were the subject of pre-operative urodynamic investigation. Various other procedures were associated with the promontofixation during the same anaesthesia: 16 tubal ligatures; 11 ovariectomies; 6 myorraphies of the anus levator muscles via the vaginal route; 2 laparoscopic sub-urethra tape procedures [8] for sphincter failure; and 80 laparoscopic colposuspensions using polypropylene tape [9] were used. This was a prospective study carried out by observation. The data were collected from the medical files and the follow-up consisted of examination 6 weeks after the operation then 6 months later still. An annual examination by one of the practitioners attached to our department provided the long-term follow-up. The main criteria studied were the pre- and post-operative anatomical situation, peroperative and immediate and late post-operative complications.

\section{Operating technique}

Patients were placed flat on the back under general anaesthesia. A bladder catheter was installed. A Pelosi uterine manipulator was installed whenever the patient still had her uterus. The pneumoperitoneum was created using a Veress needle. Four trocars were inserted: one 10-mm trocar at the umbilicus for the scope; two supra pubic $12-\mathrm{mm}$ trocars; and one $5-\mathrm{mm}$ trocar in the right iliac fossa to retract the loops of bowel, if required. Dissection started at the promontory, then the peritoneum was opened along the right border of the rectum, until the Pouch of Douglas was reached, which was completely deperitonised. The recto-vaginal fascia was dissected until the ani levator muscles were reached each side of the rectum, opening the para rectal fossae. (For the first 6 patients in the series, dissection was halted at the rectocele, without going as far as the levator muscles, and additional myorraphy was carried out via the vaginal
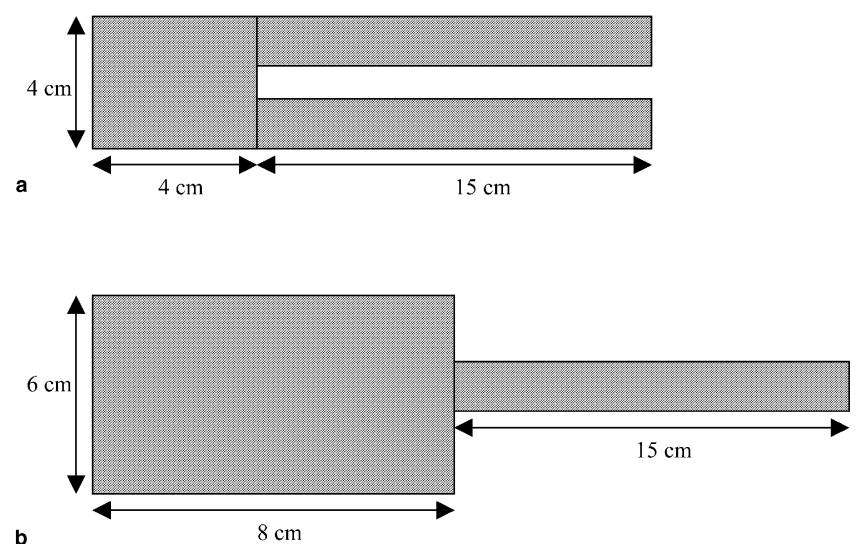

Fig. 1a,b Dimensions of the anterior (a) and the posterior (b) prosthesis

route.) Next, the vesico-vaginal fascia was dissected up to the middle third of the anterior vagina. When the patient had her uterus, it was preserved and promontofixation was carried out using a polypropylene prostheses measuring $6 \times 15 \mathrm{~cm}$ interposed between rectum and vagina, and a Yshaped strip of the same length, with the base measuring $5 \times 5 \mathrm{~cm}$, between the bladder and vagina (Fig. 1). The lower part of the posterior prosthesis was fixed using 4.8$\mathrm{mm}$ Endohernia clips on the ani levator muscles, and the upper part on the uterine isthmus at the torus uterinus. The two branches of the $\mathrm{Y}$ anterior prosthesis were taken through the broad ligament on each side of the isthmus and knotted together behind the posterior prosthesis. The anterior prosthesis was attached to the vagina with clips. Then the ends of the two prostheses were fixed without tension to the pre-vertebral ligament level with the promontory using 4-mm Endohernia clips. For vaginal vault prolapse two prostheses identical to the posterior prosthesis were used. Retropubic colposuspension was carried out systematically to prevent or treat stress urinary incontinence [9]. If the patient presented a closing pressure of less than $30 \mathrm{~cm}$ water, a sub-urethral tape was installed via laparoscopy [8].

\section{Results}

The mean operating time, including colposuspension, was $104 \mathrm{~min}$, with extremes 60 and $250 \mathrm{~min}$. The hospital stay lasted on average 4.2 days, with extremes 2 and 13 days. We deplored 15 per-operative complications in 15 patients, which are shown in Table 2. The mean drop in haemoglobin was $1.8 \mathrm{~g} / \mathrm{l}$. No transfusion was needed. The urinary catheter was left in place for a mean of 1.4 days (ranging from $24 \mathrm{~h}$ to 5 days in the bladder injury cases).

Our rate of early post operative complications is $9 \%$, involving 7 women (Table 3). The urinary infections were all treated by appropriate antibiotic therapy and did not delay the patient's departure from the hospital. The three occlusion syndromes appeared between D2 and D4 in 
Table 2 Per-operative complications

\begin{tabular}{ll}
\hline & No. of patients \\
\hline Bladder injury & 6 \\
Ureter injury & 1 \\
Vagina injury & 1 \\
Rectum injury & 1 \\
Vascular injury & 2 \\
Conversion to laparotomy & 4 \\
\hline
\end{tabular}

patients who had previously had a hysterectomy, and were treated by simple gastric aspiration. The eventration at a trocar incision site occurred on D5 and required a return to the operating theatre to close the aponeurosis. No thrombo-embolism problems were encountered. There were 25 late post-operative complications (over 1 month after the operation) in 24 patients (Table 4). The mean follow-up in our study was 53 months with 1 patient lost to follow-up. We deplored 2 cases of vaginal erosion opposite the anterior prosthesis 8-10 months after the operation, and the formation of a urinoma of the lower right ureter in another patient 2 months after the operation, discovered during investigation of ascites accompanied by abdominal pain. We noted 2 cases of de novo urinary incontinence that appeared 18 months and 2 years after the operation, together with 3 recurrences of urinary stress incontinence at 1,2 and 4 months post-operatively. Fifteen patients developed de novo constipation that was controlled by the use of laxatives and/or dietary measures. One patient presented lower pelvic pain 1 month after the operation, for which the aetiology was not found. No septic complications were noted.

Concerning our results at the present time we have been confronted with no total recurrence of prolapse. Two patients suffered a recurrence of stage $3 \mathrm{Ba}$ cystocele that appeared 2 and 4 months after surgery. Two other patients had a recurrence of cystocele, $2 \mathrm{Ba}$ in the 1 case and $3 \mathrm{Ba}$ in the other, 2 and 4 years after the operation. Two cases of recurrent rectocele occurred 2 and 3 years after promontofixation, both of which were stage- $3 \mathrm{Bp}$. There were no cases of recurrent hysterocele nor prolapse of the vaginal vault. From the functional point of view, 2 de novo cases of stress urinary incontinence appeared 18 months and 2 years post-operatively. Three cases of urinary incontinence recurred after 1,2 and 4 months. No dyspareunia, no perineal and no lumbo-sacral pain was recorded.

\section{Discussion}

Promontofixation as described by Hugier and Scali in 1957 [1] to correct genital prolapse is a recognized technique. Its reliability needs no further demonstration. The results of the various series of promontofixation via laparotomy $[10,11,12,13,14,15]$ confirm this, with a success rate of over $86 \%$ and many years of follow-up (Table 5). Global management of genital prolapse by endoscopy is more recent $[16,17,18]$ and the feasibility had still to be demonstrated. The technique is the same and the procedures used in laparotomy are reproduced with all the advantages of laparoscopy: the abdominal wall remains intact, and there is less pain and less impairment to normal health. But the great advantage of laparoscopy lies in the improved vision of the tissular components of the pelvic floor thanks to the magnified vision provided by the optic fibres and the barohaemostasis. It is far easier to identify the dissection planes,
Table 3 Early post-operative complications

Table 4 Late post-operative complications

Table 5 Results of abdominal sacrocolpopexy in the literature

\begin{tabular}{lll}
\hline & No. of patients & Early post-operative complications (\%) \\
\hline Urinary tract infection & 4 & 50 \\
Bowel occlusion & 3 & 37.5 \\
Port site eventration & 1 & 12.5 \\
Lumbo-sacral pain & 1 & 12.5 \\
\hline
\end{tabular}

\begin{tabular}{lcc}
\hline & Patients & Late post-operative complications (\%) \\
\hline Vaginal erosion & 3 & 12 \\
Volvulus of the ileum & 2 & 8 \\
Urinary stress incontinence & 5 & 20 \\
De novo constipation & 14 & 56 \\
Pelvic pain & 1 & 2.5 \\
\hline
\end{tabular}

\begin{tabular}{llll}
\hline Reference & No. of patients & Follow-up (years) & Success rate $(\%)$ \\
\hline$[10]$ & 316 & 10 & $>90$ \\
{$[11]$} & 271 & $1-11$ & 97.7 \\
{$[12]$} & 232 & $1-12$ & 91.1 \\
{$[13]$} & 203 & $1-7$ & 86.7 \\
{$[14]$} & 147 & 5 & 93 \\
{$[15]$} & 41 & 10 & 88 \\
\hline
\end{tabular}


especially during rectovaginal dissection. These technical conditions allow the posterior prosthesis to be anchored to the ani levator muscles and on each side of the vagina, thus reinforcing the posterior vaginal fascia right up to the commissure of the vulva. A learning curve is inevitable in order to take the posterior dissection beyond the rectocele to the pelvic floor. We feel this procedure is just as efficient as myorraphy of the levator muscles for the prevention and treatment of rectocele. The results of the rare series of laparoscopic promontofixation described are very encouraging. Each of these series has a success rate at short term in excess of $85 \%$; with it is true, insufficient hindsight as yet, since at least 5 years' follow-up is necessary. These results are comparable to those of our series $(94 \%)$ [19, 20, 21, 22].

The characteristics of the population studied in our work are comparable to those described in the literature $[12,13,18,21,22]$. The mean age of our patients (55 years) is identical. Forty-five percent of our patients were past the menopause, which for certain authors is proof of good results since they find a connection between advancing age, the menopause and poor results $[12,23]$. The mean weight of the patients gives rise to no particular comment. The per-operative complications encountered in the various series published, whether with laparoscopy or with laparotomy, are of the same types: they can be resumed as organ and vascular injuries [24].

Our per-operative rate of complications is practically the same (15\%) as other laparoscopic series $(5-12 \%)$ [18, $21,22]$. Bladder injury is the main complication, whether with laparoscopy or laparotomy, with a mean frequency of 5\% [20]. In our experience the 6 bladder injuries occurred in patients with a prior history of hysterectomy. Our rate of conversion to laparotomy (4\%) is comparable to those in the other laparoscopic series: 3 for multiple adhesions in the true pelvis and the fourth for an anatomical variation (bifurcation of the vena cava too low). Our per-operative complications occurred with the same frequency from beginning to end of the series. Our operating time is considerably shorter, probably due to the use of clips to fix the prostheses and the choice not to carry out any hysterectomy.

Concerning the post-operative complications and notably those connected with the prostheses $[4,25]$ : major prolapse is comparable to hernia of the abdominal wall, which is a hernia due to a weakness that requires the use of prosthetic material $[25,26,27]$ to reinforce the damaged connective tissue in the fascias. We had three complications of this type; the first was a fistula of the lower ureter which required uretero-vesical reimplantation via laparotomy without ablation of the prosthesis. No urinary fistula has been described in the literature with this technique to date. Our two other complications consisted of anterior vaginal erosions opposite the prosthesis, a complication which exists in the literature [28]. Our percentage of erosion (2\%) is perfectly in line with that described in the other series published $[4,11,20,29$, $30,31]$. The appropriate treatment consists of exeresis of the fragment of mesh exposed by the erosion via the vagina, followed by vaginal suture after freshening the edges to be sutured, without any incidence on the anatomical or functional results. In all the series published these prostheses are fixed using non-resorbable suture material. The specific characteristic of our series lies in the fact that we fix the strips in position using Endohernia clips, which makes the procedure easier. We do not feel there is any greater risk of transfixing the vagina that with sutures.

The occlusion syndrome is a complication generally reported with a frequency of $1.5-3 \%$ depending on the series $[11,12,30,32]$. Any abdominal operation runs this risk, and the existence in addition of a deep pelvic fossa crossed in the anterio-posterior direction by prosthetic material increases this risk. The occurrence of occlusion is connected in the great majority of cases with a defect in peritonisation. To help avoid this complication certain authors, such as Cosson et al. [20] and Lefranc and Blondon [10], recommend sub-total or even total hysterectomy in order to make peritonisation easier, for this is recognised as being difficult when the uterus remains in place $[33,34]$. In our series, all the occlusion problems occurred in patients who had a prior history of hysterectomy, which thus contradicts this theory. We observed no case of spondylodiscitis in our study, despite the vaginal, bladder and rectal injuries. The same is true for the other laparoscopy series [35, 36]. The other complications reported in the literature for laparotomy are parietal sepsis and pulmonary embolism, which have not been mentioned with the laparoscopic route.

Study of the anatomical and functional results for laparoscopic prolapse repair is not very satisfactory as yet because of the variety of techniques depending on the surgeon, and the low number of patients covered by the reports published. There is no randomized study allowing any statement to the effect that the results of laparoscopic promontofixation might be comparable to those obtained by laparotomy. According to the literature, recurrence of prolapse after promontofixation most often takes the form of posterior colpocele. This could be explained by inadequate posterior dissection that leaves the rectoceles intact. Moreover, certain operators simply install a single anterior prosthesis without addressing the posterior aspect [4]. Both cases of recurrence of rectocele in our series can probably be explained by inadequate dissection or by an early shift in position of the prosthesis, before collagen colonization. While the two delayed recurrences concerning the anterior vagina may be due to the same reason, the two early recurrences would appear to be more probably connected with incomplete dissection and repair resulting in persistence of the fascia lesion. From the functional point of view, notably urinary, we have a $3 \%$ rate of recurrence of stress urinary incontinence, which is in agreement with other published results (between 4 and 9\%); however, our series is the only one using laparoscopy to have noted two cases of de novo stress urinary incontinence 18 months and 2 years later. These patients had a normal urodynamic pre-operative work-up and colposuspension was carried out as a routine. 
From the sexual point of view, no dyspareunia has been reported in the laparoscopic series, and the same holds true for ours; however, depending on the series, 10 $25 \%$ of patients complain of this after surgery by laparotomy [37, 38].

With respect to bowel function, a reproach made for promontofixation is that it results in post-operative constipation [33, 39]. Our results confirm this since de novo constipation represents $56 \%$ of late post-operative complications. The mechanism behind this constipation is similar to the dyschezia found after rectopexy and is difficult to analyse, but it is possible that apart from rectal denervation problems a certain rigidity in the fixing could also be involved.

Surgical correction of genital prolapse by promontofixation is the result of several decades of evolution in the technique. In view of the results of our series, compared with the literature, the use of laparoscopy to carry out promontofixation appears to present many advantages for treating prolapse in young women. The fact that at medium term laparoscopy gives comparable results to those obtained with laparotomy, but in less aggressive fashion, makes it very attractive. It is easier to reproduce in patients with no past history of pelvic surgery, since the cleavage planes are less difficult to find and dissect; however, the learning curve is relatively long and requires considerable experience in laparoscopy. Once it has been mastered, this technique also needs sufficient numbers of patients for pelvic statics surgery in order to maintain the required level of skill. The technique for correction of prolapse by laparoscopic promontofixation is still being assessed and is reserved for trained surgeons working in specialized teams, allowing the procedures to be carried out under optimum safety conditions. When this is so, it allows patients to be offered surgical treatment with no added complications.

Acknowledgement We thank M. Dreyfus for his advice on methodology and for the production of this article.

\section{References}

1. Hugier J, Scali P (1957) La suspension postérieure au disque lombo-sacré. Gynecol Obstet 56:94-98

2. Kamina P, Chansigaud JP (1988) Soutènement et suspension des viscères pelviens chez la femme. J Gynecol Obstet Biol Reprod 17:835-848

3. Angulo A, Kligman I (1989) Retroperitoneal sacrocolpopexy for correction of prolapse of vaginal vault. Surg Gynecol Obstet 169:319-323

4. Blanc B, Franquebalme JP, Agher JP, Conte M, Grectas MJ, Ruf H (1985) Les prolapsus génitaux. A propos d'une série de 220 cas. Rev Fr Gynecol Obstet 80:713-721

5. Constantin S, Iosif CS (1993) Abdominal sacral colpopexy with using of synthetic mesh. Acta Obstet Gynecol Scand 72:214217

6. Scali P, Blondon J, Gerard M (1974) Les opérations de soutènement-suspension par voie haute dans le traitement des prolapsus vaginaux. J Gynecol Obstet Biol Reprod 3:365-378

7. Bump RC, Mattiasson A, Bo K, Brubaker LP, DeLancey JOL, Klarskov P, Shull BL, Smith ARB (1996) The standardization of terminology of female pelvic organ prolapse and pelvic floor dysfunction. Am J Obstet Gynecol 175:10-17

8. Theobald P von, Lucas J, Barjot P, Cheret A, Grosdemouge I, Herlicoviez M (1999) Faisabilité de la fronde sous uréthrale coelioscopique. J Gynecol Obstet Biol Reprod 28:529-533

9. Theobald P von, Guillaumin D, Levy G (1995) Laparoscopic preperitoneal colposuspension for stress incontinence in women. Technique and results of 37 procedures. Surg Endosc 9:1189-1192

10. Lefranc JP, Blondon J (1983) Chirurgie des prolapsus génitaux par voie abdominale. J Chir 120:431-436

11. Ocelli B, Marducci F, Cosson M, Ego A (1999) La promontofixation par voie abdominale dans la cure des prolapsus génitaux féminins avec ou sans incontinence urinaire. A propos de 271 cas. Ann Chir 53:367-377

12. Deval B, Fauconnier A, Repiquet D, Liou Y, Montuclard B (1997) Traitement chirurgical des prolapsus génito-urinaires par voie abdominale. A propos d'une série de 232 cas. Ann Chir 51:256-265

13. Lecuru F, Taurelle R, Clouard C, Attal JP (1994) Traitement chirurgical des prolapsus génito-urinaires par voie abdominale. Résultats d'une série continue de 203 interventions. Ann Chir 48:1013-1019

14. Snyder TE, Krantz KE (1991) Abdominal retroperitoneal sacral colpopexy for the correction of vaginal prolapse. Obstet Gynecol 77:944-949

15. Valattis SR, Stanton SL (1994) A retrospective study of a clinician's experience. Br J Obstet Gynecol 101:518-522

16. Mage G, Wattiez A, Pomel C, Canis M, Pouly JL, Bruhat MA (1996) Limites de la prise en charge coelioscopique des troubles de la statique pelvienne en gynécologie. Presse Med 25:2037-2041

17. Smith ARB (1995) Laparoscopic surgery for incontinence and genito-urinary prolapse. Curr Opin Obstet Gynecol 7:397-399

18. Wattiez A, Boughizane S, Alexandre F, Canis M, Mage G (1995) Laparoscopic procedures for stress incontinence and prolapse. Curr Opin Obstet Gynecol 7:317-321

19. Cheret A, Theobald P von, Lucas J, Dreyfus M, Herlicoviez M (2001) Faisabilité de la promontofixation par voie coelioscopique. Série prospective de 44 cas. J Gynecol Obstet Biol Reprod 30:139-143

20. Cosson M, Bogaert E, Narducci F, Querleu D, Crepin G (2000) Promontofixation par coelioscopie: résultats à court terme et complications chez 88 patientes. J Gynecol Obstet Biol Reprod 29:746-750

21. Mahendran D, Prasmar S, Smith ARB, Murphy O (1996) Laparoscopic sacrocolpopexy in the management of vaginal vault prolapse. Gynecol Endosc 5:217-222

22. Nezhat C.H, Nezhat F, Nezhat C (1994) Laparoscopic sacralcolpopexy for vaginal vault prolapse. Obstet Gynecol 84:885888

23. Fantl JA, Cardozo L, McClich DK (1994) Estrogen therapy in the management of urinary incontinence in post-menopausal women: a meta-analysis. First report of the hormones and urogenital therapy committee. Obstet Gynecol 83:12-18

24. Sutton GP, Addisson WA, Livengood CH, Hammond CB (1981) Life threatening hemorrhage complications of sacral colpopexy. Am J Obstet Gynecol 140:836-837

25. Brown GL, Richardson D, Malangoni MA, Tobin GR, Ackerman D, Polk HC (1985) Comparison of prosthetic materials for abdominal wall reconstruction in the presence of contamination and infection. Ann Surg 201:705-711

26. Law NW, Ellis H (1988) Adhesion formation and peritoneal healing on prosthetic materials. Clin Mater 3:95-101

27. Ridley JH (1976) A composite vaginal vault suspension using fascia lata. Am J Obstet Gynecol 126:590-596

28. Timmons MC, Addisson WA (1997) Mesh erosion after abdominal sacral colpopexy. J Pelvic Surg 3:75-80

29. Cundiff GW, Harris RL, Coartes K, Low V, Bump RC, Addisson WA (1997) Abdominal sacral colpoperineopexy. A new approach for correction of posterior compartment defects 
and perineal descent associated with vaginal vault prolapse. Am J Obstet Gynecol 177:1345-1355

30. Dagorne JM, Lemoine JP, Duval CL, Villiere J (1987) Cure des prolapsus génitaux par voie abdominale et avec matériel prothétique. Analyse d'une série de 40 observations. Rev Fr Gynécol Obstét 82:151-155

31. Volz J, Strittmatter E, Volz E, Koster S, Wischnik A, Melchert F (1993) Die pelviskopische Sakropexie zur Therapie des vaginal Prolapses. Geburtsh Frauenheilk 53:705-708

32. Addison WA, Timmuns MC, Wall LL, Livengood CH (1984) Failed abdominal sacral colpopexy. Observations and recommendations. Obstet Gynecol 74:480-482

33. Villet R, Morice P, Bech A (1993) Approche abdominale des rectocèles et des élytrocèles. Ann Chir 41:626-630

34. Wetzel O, Katmeh S, Plougastel-Lucas ML, Bourdon J (1995) Traitement des prolapsus génito-urinaires par promontofixation à l'aide d'un matériel prothétique associé à une hystérectomie totale; complications et résultats à propos d'une série de 55 observations. Progrès Urol 5:221-230
35. Cailleux N, Daragon A, Laine F, Deshayes P et al. (1991) Spondylodiscites infectieuses après cure de prolapsus génital. A propos de 5 cas. J Gynecol Obstet Biol Reprod 20:1074-1078

36. Seneze J (1991) A propos des spondylodiscites infectieuses après cure de prolapsus génital. J Gynecol Obstet Biol Reprod 20:448

37. Fatton B, Grunberg P, Phana M, Mansoor A, Descamps C, Jacquetin B (1993) Cure de prolapus chez la femme jeune : la voie abdominale n'a pas d'avantage sur la voie vaginale. A propos d'une étude prospective randomisée. Résultats fonctionnels et évaluation de la qualité de vie. J Obgyn 1:133-43

38. Graig GA, Jackson P (1975) Letter: sexual life after vaginal hysterectomy. Br Med J 3:97

39. Dolk A, Broden G, Holmstrom B, Johansson C, Nilsson BY (1990) Slow transit of the colon associated with severe constipation after the Ripstein operation. A clinical and physiologic study. Dis Colon Rectum 33:786-790 